\title{
RUANG EDUKASI DAN INTERAKSI MUARA ANGKE
}

\author{
Nathaniel Edbert ${ }^{1)}$, Dewi Ratnaningrum ${ }^{2)}$ \\ 1)Program Studi S1 Arsitektur, Fakultas Teknik, Universitas Tarumanagara, lawrence.edbert@gmail.com \\ 2)Program Studi S1 Arsitektur, Fakultas Teknik, Universitas Tarumanagara, dewir@ft.untar.ac.id
}

\begin{abstract}
Abstrak
Muara Angke merupakan salah satu kawasan miskin yang ada di Jakarta. Salah satu penyebabnya adalah kurangnya pendidikan yang dimiliki oleh penduduk sekitar sehingga banyak keluarga yang tidak memiliki kehidupan yang baik. Selain itu, sebagai salah satu kawasan yang berada di pinggir laut, kawasan Muara Angke merupakan salah satu daerah yang sibuk dengan aktivitas pergudangannya yang memperdagangkan hasil laut sehingga sebagian tanah yang ada digunakan sebagai tempat bekerja dan tempat berdagang. Hal ini menimbulkan masalah pada kawasan ini, seperti berkurangnya lahan hijau dan ruang publik untuk penduduk sekitar. Hasil pengamatan, data-data, dan aspirasi kebutuhan masyarakat yang sudah dikumpulkan akan membentuk bangunan yang akan menjawab masalah tersebut dengan rancangan proyek yang akan menerapkan konsep tempat ketiga yang diperkenalkan oleh Ray Oldenburg, kemudian akan menggunakan pendekatan arsitektur regionalisme dalam membangun desain dan material pada bangunan ini. Proyek akan menjadi ruang interaksi warga sekitar yang memiliki fungsi utama sebagai wadah kegiatan penduduk sekitar dan fungsi sampingan yang mendukung potensi wisata kuliner untuk melayani pengunjung luar dengan konsep bangunan yang menyerupai oase pada kawasan yang padat ini. Selain menjadi tempat hiburan, bangunan ini juga akan menjadi wadah edukasi bagi masyarakat lokal yang mengajarkan mereka agar dapat memiliki pendidikan yang baik untuk membantu kehidupan mereka.
\end{abstract}

Kata kunci: edukasi; muara angke; nelayan; ruang interaksi

\begin{abstract}
Muara Angke is one of the poorest areas in Jakarta. One of the reasons is the lack of education owned by the surrounding population so that many families do not have a good life. In addition, as one of the areas located on the seafront, the Muara Angke area is one area that is busy with warehousing activities that trade in marine products so that part of the existing land is used as a place to work and trade. This causes problems in this area, such as the reduction of green land and public space for the surrounding population. The observations, data, and aspirations of community needs that have been collected will form a building that will answer the problem with a project design that will apply the third place concept introduced by Ray Oldenburg, then will use the architectural approach of regionalism in building designs and materials in buildings this. The project will be a space for interaction of local residents who have the main function as a container for the activities of surrounding residents and side functions that support the potential of culinary tourism to serve outside visitors with the concept of buildings that resemble oases in this dense area. In addition to being a place of entertainment, this building will also be a place of education for local people who teach them to be able to have a good education to help their lives.
\end{abstract}

Keywords: education; fisherman; interaction space; muara angke 


\section{PENDAHULUAN}

\section{Latar Belakang}

Kampung Nelayan Muara Angke, Jakarta Utara, pada awal perkembangannya merupakan salah satu kawasan yang kaya akan keanekaragaman alam dan budaya tradisional. Potensi alam dan kearifan lokal tersebut dapat dimanfaatkan dan dikembangkan menjadi salah satu daerah tujuan wisata unggulan di Jakarta. Hal tersebut didukung oleh letaknya yang dekat dengan Hutan Lindung Muara Angke dan berbatasan langsung dengan perairan, yaitu Laut Jawa, Kali Asin, dan Kali Adem. Selain itu, Kampung Nelayan Muara Angke yang dikenal sebagai lokasi pelelangan dan pelabuhan ikan memiliki tatanan kehidupan penduduk sekitar dengan sebagian besar penduduk bermatapencaharian sebagai nelayan dan pengolah hasil perikanan yang mempunyai keterkaitan dengan sumber daya yang mereka miliki. Namun, potensi-potensi dari Kampung Nelayan Muara Angke, tersebut mulai luntur karena pengembangan fisik yang kurang mendukung.

Sebagai kawasan kecil yang menjadi tempat tinggal dan tempat bekerja masyarakat lokal, kawasan ini terkesan sangat padat karena banyaknya masyarakat yang bekerja juga di rumahnya, Mayoritas masyarakat berprofesi sebagai nelayan dan banyak nelayan yang tidak memiliki modal yang besar sehingga terkadang menggunakan metode penangkapan yang merusak lingkungan. Dengan pendidikan yang kurang, nelayan kecil ini kalah bersaing dengan nelayan bermodal besar sehingga berpenghasilan kecil. Akibatnya nelayan kecil membuka usaha yang menggunakan lahan di samping tempat tinggalnya. Hal ini menyebabkan kurangnya lahan hijau sehingga terkesan gersang. Maka dari itu perlu adanya ruang yang lega di kawasan yang padat ini.

Ray Oldenburg menawarkan sebuah konsep third place, dimana konsep ini menciptakan ruang baru yang menjadi ruang relaksasi di luar dari rumah dan tempat kerja. Pada ruang ini, masyarakat dapat melakukan hal-hal yang memberikan kesenangan pribadi maupun kelompok tanpa merasakan tekanan dari orang lain karena tempat ini dapat menerima semua orang. Kawasan yang terletak pada daerah pesisir biasanya memiliki keistimewaan pada lingkungannya yang mempengaruhi arsitektur kawasan tersebut. Iklim dan kondisi lingkungan yang berbeda dari tengah-tengah kota menjadi pertimbangan dalam mendirikan bangunan. Kari Jormakka menawarkan metode regionalisme dalam menjawabnya. Dengan metode ini, akan memudahkan dalam membentuk bangunan yang dapat berdiri dan berbau dengan kondisi alam dan iklim pada kawasan ini.

\section{Rumusan Permasalahan}

a. Masyarakat tidak memliki ruang bekumpul yang aman dan nyaman akibat dari padatnya kondisi kawasan ini.

b. Nelayan-nelayan kecil yang tidak dapat bersaing dengan nelayan bermodal besar sehingga menggunakan segala cara untuk mendapatkan penghasilan yang cukup.

c. Kurangnya ruang publik penunjang kegiatan penduduk lokal.

\section{Tujuan}

a. Memberikan wadah berkumpul masyarakat yang aman, nyaman, untuk masyarakat lokal mulai dari para orang tua sebagai nelayan hingga anak - anak yang masih bermain - main sebagai tempat berkumpul, berinteraksi dan beraktivitas bersama sebagai third place.

b. Memberikan wadah komunitas nelayan untuk dapat diberdayakan agar dapat meningkatkan kesejahteraan kehidupannya.

c. Membangun fasilitas tambahan seperti fasilitas wisata kuliner sebagai tempat wisata bagi pengunjung kawasan lokal maupun luar kampung yang mengunjungi kawasan ini. 


\section{KAJIAN LITERATUR}

\section{The Great, Good, Place}

"The Great Good Place", buku oleh Ray Oldenburg mengatakan bahwa Third Place merupakan tempat ketiga yang dibutuhkan oleh masyarakat selain First Place (tempat tinggal) dan Second Place (tempat kerja). Third Place juga merupakan sebuah wadah yang dijadikan sebagai tempat untuk berkumpul, berinteraksi, dan bersosialisasi antar manusia dengan tujuan agar manusia dapat menjadi pribadi yang peduli terhadap sesamanya. Terdapat beberapa karakteristik dari Third Place, antara lain:

\section{a. On Neutral Ground}

Tempat yang boleh didatangi oleh orang-orang yang dengan bebas dapat datang dan pergi. Serta tempat orang-orang dapat melakukan aktifitas yang netral, tidak ada unsur sensitif seperti agama dan politik.

b. The Third Place as Leveler

Tempat yang inklusif, bebas untuk siapa saja. Merupakan wadah berkumpul orang-orang untuk saling berinteraksi tanpa perlu memiliki tujuan.

c. Conversation is The Main Activity

Tempat ini bertujuan agar orang-orang saling berinteraksi. Dengan saling berinteraksi, orang- orang dapat menunjukkan proses pengembangan untuk saling toleran satu sama lain.

d. Accessibility and Accommodation

Third Place harus dapat menghadirkan kenyamanan dan rasa aman kepada para pengunjung sepanjang hari, dari pagi hari hingga malam hari.

e. The Regulars

Third Place harus menciptakan rasa penerimaan yang baik sehingga pengunjung baru dapat betah berada disana dan ingin kembali lagi.

f. A Low Profile

Third Place tidak berusaha terlihat menonjol di kawasannya.

g. The Mood is Playful

Walaupun third place memiliki kesan low profile, tetap harus memiliki rasa playful di dalamnya, agar tidak menciptakan kebosanan dan dapat memberikan rasa nyaman pengunjungnya.

h. A Home Away from Home

Third Place perlu memiliki rasa yang nyaman, bagaikan berada di rumah sehingga pengunjung dapat meredakan kepenatan dalam aktivitas sehariannya.

\section{Sustainable Architecture}

Sustainable Architecture (arsitektur berkelanjutan) menurut Adrian Pitts memiliki tujuan untuk mencapai kesadaran lingkungan dan memanfaatkan sumber daya alam yang berkelanjutan kualitasnya dan daya dukungnya dalam rangka untuk tetap dapat menjalankan proses pembangunan yang terus berkelanjutan juga serta menciptakan arsitektur yang harmonis dengan lingkungan dan penekanan pada prinsip meminimalkan kerusakan dan memaksimalkan pemanfaatan lingkungan alami. Sustainable Architecture memiliki 3 komponen utama yaitu keberlanjutan ekonomi, keberlanjutan lingkungan, dan keberlanjutan sosial.

\section{Keberlanjutan Ekonomi}

Menurut Adrian Pitts, permasalahan yang sering terjadi di kota-kota besar maupun kecil adalah pada sektor perekonomian. Keterbatasan dana menjadi kendala utama dalam keberlanjutan bangunan jangka panjang baik dari segi fungsi maupun perawatan, khususnya bangunan milik pemerintah. 
Kerusakan hubungan antar lingkungan banyak disebabkan oleh pengembangan bangunan yang hanya jangka pendek dan tidak sesuai dan tepat sasaran, perlunya pengembangan jangka panjang sangat penting dalam konsekuensi perkembangan ekonomi skala kota. Salah satu strategi perencanaan dalam pembangunan adalah dengan menggabungkan beberapa fungsi tipologi bangunan yang dapat menciptakan keterkaitan sehingga dapat menghasilkan profit untuk keberlanjutan bangunan dari segi fungsi ataupun maintenance jangka panjang. Pemilihan penggunaan material dan konstruksi juga dapat menekan biaya pembangunan, dengan meggunakan material lokal dapat menekan biaya transportasi material dan mudah dalam perawatan jangka panjang. Selain untuk menekan biaya pembangunan Penggunaan material lokal juga dapat membantu mengembangkan perekonomian daerah.

\section{Keberlanjutan Sosial}

Keberlanjutan sosial membahas detail bagaimana karakteristik eksternal bangunan dengan lingkungan sekitar, tata kota, sistem transportasi, pola permukiman daerah. Dalam membangun lingkungan baru perlu terdapat 3 skala dasar yaitu the region, the neighborhood, dan the building. The region merupakan perbandingan antara kota, wilayah, dan masyarakat, dimana pembangunan masa depan harus mengerti pengembangan ruang yang akan dibangun dengan besaran kota lokasi dan hubungannya dengan kota. Prinsip spesifiknya antara lain; pada kota metropolitan mempunyai hal penting antara lain lingkungan hidup, ekonomi, hubungan budaya, lahan produktif, dan pemandangan yang ada; melestarikan sumber daya alam, investasi ekonomi, dan struktur sosial kota; pengembangan kawasan baru harus terorganisir dengan lingkungan atau kawasan yang sudah ada; harus menguntungkan bagi masyarakat; harus mendukung penggunaan transportasi masal; pendapatan dan sumber daya harus terbagi rata.

Bangunan utama pada kawasan berhubungan dengan lingkungan sekitar, umumnya harus mempertimbangkan area pejalan kaki yang baik, karakter dan identitas bangunan yang unik, mengembangkan fasilitas umum yang bisa digunakan bersama. Prinsip yang spesifik antara lain; Lingkungan harus padu, area pejalan kaki yang baik (pedestrian friendly); Jalan harus terkoneksi atau mendorong pejalan kaki dan penggunaan transportasi umum masal. Pada skala ini berhubungan dengan membangun sebuah lingkungan antara bangunan dengan lansekap. Prinsip yang spesifik antara lain; tugas utama pada seluruh arsitektur kota ataupun lansekap adalah mendefinisikan fisik jalan dan ruang publik sebagai ruang bersama; proyek arsitektur harus tanggap terhadap lingkungan mereka dan penyelesaian masalah harus melampaui gaya bangunan; ruang terbuka hijau dan jalan harus aman, nyaman, dan bersahabat dengan pejalan kaki. Mengkonfigurasi dengan benar mendorong masyarakat untuk berjalan kaki dan memungkinkan interaksi antar tetangga untuk saling mengenal sehingga dapat melindungi komunitas mereka.

Dijelaskan bahwa ada 3 elemen penting dalam proses membangun sebuah lingkungan sosial yaitu connectivity, bagaimana desain dapat memperkuat hubungan antara bangunan, site, community dan ekologi. Memperkuat karakteristik lokasi secara spesifik dan alami; indigeneous, cara membuat desain yang seimbang dengan aktivitas serta aksesibilitas penduduk asli yang ada di sekitar site, dan dapat menjadi keberlanjutan positif ke masa depan; long life, loose fit, bagaimana membuat desain untuk generasi dimasa datang tetapi tetap mencerminkan generasi-generasi sebelumnya.

\section{Keberlanjutan lingkungan hidup}

Desain bangunan juga dapat mempengaruhi keberlanjutan lingkungan yang sudah ada dan mempengaruhi lingkungan baru yang akan dibuat. Desain bangunan merupakan peran penting 
dalam efisiensi pemanfaatan energi yang ada di lingkungan terhadap bangunan yang akan di bangun, beberapa hal yang dapat direncanakan adalah:

a. Plan Form

Rencana bentuk menjadi sangat signifikan dalam efisiensi energi pada desain, ketinggian bangunan akan mempengaruhi penggunaan cahaya buatan maupun pengaturan suhu buatan.

b. Orientation

Orientasi hadap bangunan mempengaruhi dalam penerimaan panas matahari dan cahaya matahari yang masuk ke dalam bangunan.

c. Glazing Ratio

Rasio penggunaan kaca menjadi berpengaruh terhadap fasad bangunan sendiri. Jendela dan penggunaan kaca merupakan bagian dari pengaturan cahaya, suhu yang masuk ke dalam bangunan. Keseimbangan mengikuti fungsi dari orientasi, lokasi, halangan dan kebutuhan pengguna. Umumnya antara rasio $25 \%-45 \%$ dianggap sebagai penggunaan yang optimal dan juga tergantung dari beberapa faktor yaitu desain jendela yang dapat mengoptimalkan kebutuhan udara alami.

\section{METODE}

Penulis melakukan studi lapangan dengan pengamatan langsung pada lokasi. Pengamatan yang dilakukan berupa pengamatan yang tertuju pada kegiatan dan waktu aktivitas yang biasa masyarakat lakukan sehari-hari kemudian melakukan pengumpulan data dengan mewawancarai beberapa masyarakat di sana. Kemudian langkah selanjutnya adalah mengidentifikasi masalah yang ada. Dari pengamatan tersebut juga ditemukan beberapa masalah pada kawasan yang sekiranya perlu untuk diatasi. Kemudian dari semua data dan masalah yang sudah didapatkan, penulis berusaha menjawab permasalahan dan kebutuhan masyarakat yang dikembangkan menjadi ide program dan rancangan bangunan. Selain melakukan pengamatan, Langkah selanjutnya yang dilakukan untuk mengolah data adalah dengan mengkaji teori-teori yang berhubungan dengan proyek ini. Penulis melakukan studi literatur berupa buku, jurnal dan akses internet untuk menambahkan dan melengkapi datadata yang sudah diperoleh. Penulis juga melakukan studi preseden dengan tema dan konsep yang menyerupai proyek ini sehingga mendapatkan gambaran untuk hasil rancangan proyek ini.

Dalam melakukan perancangan, penulis mencari metode pendekatan dan perancangan untuk merancang bangunan ini. Metode pendekatan yang digunakan adalah pendekatan tindakan sehari hari atau behaviour yang memperhatikan kegiatan normal sehari-hari masyrayakat untuk membentuk program yang sesuai kebutuhan. Kemudian metode perancangan yang digunakan adalah metode regionalisme yang memperhatikan kondisi lokal dari iklim, keadaan lingkungan dan kondisi sekitar sehingga bangunan yang akan dirancang dapat menjadi satu kesatuan dengan lingkungan dan tidak merusak lingkungan. Setelah melakukan semuanya, penulis menggabungkan data dengan teori serta metode yang sudah dikaji sehingga menghasilkan usulan program yang sekiranya dapat menjawab masalah yang sudah diidentifikasi. Setelah itu, usulan program disesuaikan dengan elemen pembentuk ruang sehingga menghasilkan sebuah bangunan.

\section{DISKUSI DAN HASIL}

Konsep yang diterapkan bangunan ini menerapkan konsep menyerupai 'oase', yaitu sebagai daerah subur yang berada di tengah-tengah gurun, yang diterapkan pada kawasan yang padat dan gersang seperti di Muara Angke. Konsep ini muncul berdasarkan hasil observasi pada kawasan ini, dimana pada kawasan ini sangat padat dan minimnya ruang hijau terbuka sehingga diharapkan bangunan ini dapat menjadi ruang refreshing sehari-hari bagi masyarakat. 
Bentuk awal mengikuti bentuk tapak, berbentuk kotak menyesuaikan lingkungan sekitar. Kemudian melalui analisis dari pola pergerakan masyarakat dan akses sirkulasi yang ada di kawasan ini maka muncul bentuk yang diolah seperti gambar di atas. Juga melihat dari rencana jalan yang menyebabkan besarnya jalur air sehingga dapat membuka jalur perahu nelayan untuk dapat mengakses langsung bangunan ini.

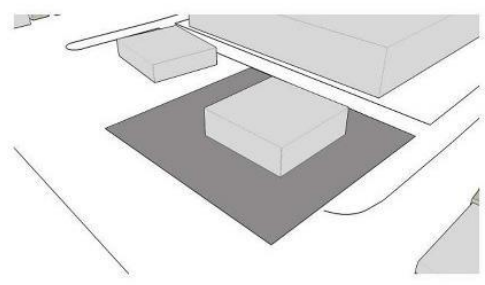

Bentuk dasar berupa sebuah kotak, kontekstual dengan kondisi kawasan tersebut.

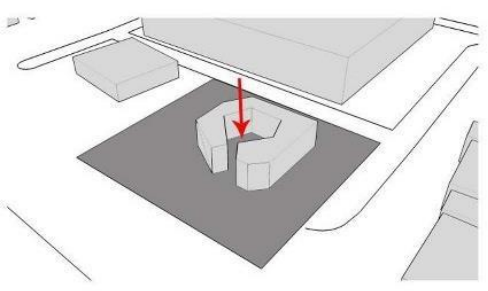

Memberikan void pada tengah massa agar terkesan ringan dengan bentukyang pipih.

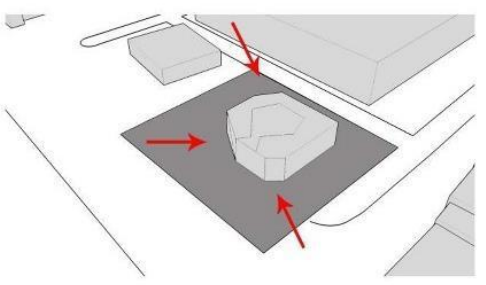

Memberi potongan potongan yang dapat memberikan kesan menyambut pada segala sisi karena tapak ini dapat diakses dari segala arah

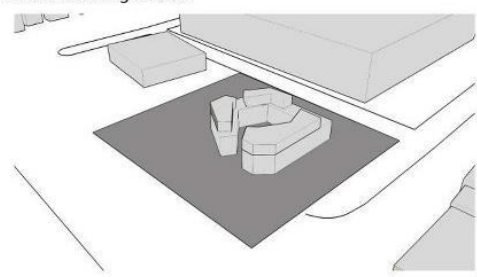

Memberikan massa tingkat dengan mengikuti bentuk podium yang sudah ada.

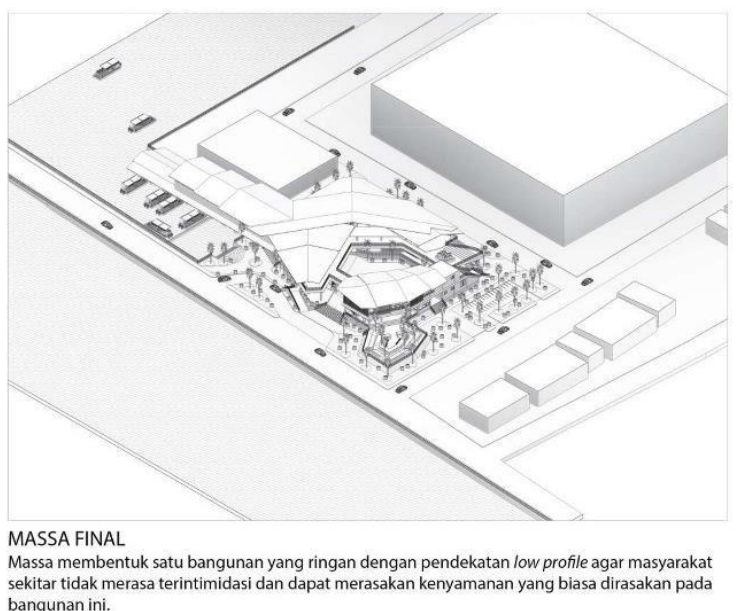

Gambar 1. Proses Gubahan Massa

Sumber: Dokumentasi Pribadi, 2020

\section{Program Ruang}

Sesuai dengan tema soal mengenai Third Place, bangunan ini dibangun untuk membantu aktivitas serta kebutuhan masyarakat. Berdasarkan hasil survei dan analisis, pengguna tetap merupakan warga lokal Muara Angke dengan warga luar sebagai pengunjung lokasi. Maka dari itu dominasi program ruang ditujukan untuk masyarakat lokal sebagai tempat hiburan dan berkumpul serta tempat untuk mendapatkan pelatihan dari pihak luar maupun oleh perkumpulan masyarakat lokal. Kemudian terdapat juga program untuk masyarakat luar sebagai pengunjung yang menjadi konsumen dari hasil laut yang dihasilkan oleh penduduk lokal sehingga kegiatan untuk masyarakat luar ini dapat memberikan pemasukan bagi masyarakat lokal. 
Tabel 1. Program Ruang

\begin{tabular}{|c|c|c|c|c|}
\hline & No. & Nama Ruang & Fungsi Ruang & Sasaran Pengguna \\
\hline \multirow{12}{*}{ 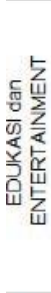 } & \multirow{4}{*}{1} & \multirow{4}{*}{ Ruang Edukasi } & Sharing Nelayan & \multirow{4}{*}{ Nelayan } \\
\hline & & & Pelatihan Memancing & \\
\hline & & & Bimbingan dan Pembinaan & \\
\hline & & & Pendidikan Mekanisme Pemasaran & \\
\hline & \multirow{7}{*}{2} & \multirow{7}{*}{ Ruang Workshop } & Pelatihan Pengolahan & \multirow{7}{*}{ Ibu - Ibu Nelayan } \\
\hline & & & Memilah & \\
\hline & & & Mencuci dan Megeringkan & \\
\hline & & & Mengupas Kerang & \\
\hline & & & Memotong dan Menempel & \\
\hline & & & Melapisi Produk & \\
\hline & & & Pelatihan Kerajinan Kulit lkan & \\
\hline & 3 & Ruang Pameran & Memajang Hasil Workshop & Semua Pengunjung \\
\hline \multirow{4}{*}{$\frac{\vec{z}}{\underline{\underline{u}}}$} & \multirow{2}{*}{1} & \multirow{2}{*}{ Restoran } & Menikmati Hidangan Laut & \multirow{4}{*}{$\begin{array}{l}\text { Pengunjung Luar } \\
\text { Masyarakat Lokal }\end{array}$} \\
\hline & & & Tempat Berkumpul Bersama & \\
\hline & \multirow{2}{*}{2} & \multirow{2}{*}{ Tempat Penjualan Aksesoris } & Transaksi Jual Beli Barang & \\
\hline & & & Melihat Display Aksesoris Laut & \\
\hline \multirow{8}{*}{$\frac{\sqrt{\frac{1}{2}}}{\frac{2}{2}}$} & \multirow{7}{*}{1} & \multirow{7}{*}{ Taman Tengah } & Tempat Anak-Anak Nelayan Bermain & \multirow{8}{*}{$\begin{array}{c}\text { Anak - Anak } \\
\text { Nelayan } \\
\text { Ibu - lbu Nelayan } \\
\text { Nelayan } \\
\text { Masyarakat Lokal } \\
\text { Pengunjung Luar }\end{array}$} \\
\hline & & & Tempat Berkumpul Masyarakat & \\
\hline & & & Tempat Relaksasi & \\
\hline & & & Tempat Acara Lokal & \\
\hline & & & Tempat Acara Keagamaan & \\
\hline & & & Tempat Budaya Lokal & \\
\hline & & & Tempat Istirahat Nelayan & \\
\hline & 2 & Balai Warga & Tempat Kegiatan (Tidak Permanen) & \\
\hline \multirow{7}{*}{ 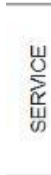 } & 1 & Toilet & Buang Air & Semua Pengunjung \\
\hline & 2 & Ruang ME & Tempat Kelistrikan & \multirow{6}{*}{ Pengelola } \\
\hline & 3 & Ruang Pengelola & Mengelola Bangunan & \\
\hline & 4 & Ruang Sampah & Penampungan Sampah & \\
\hline & 5 & Gudang & Menyimpan Barang & \\
\hline & 6 & Loading Dock & Memasukan Barang & \\
\hline & 7 & Dapur & Mengelola Makanan & \\
\hline
\end{tabular}

Sumber: Dokumentasi Pribadi, 2020

\section{Struktur}

Bangunan menggunakan material beton sebagai struktur kolom, balok serta plat lantai dengan jarak antar kolom sebesar 5 meter. Kolom beton berdimensi $60 \times 60 \mathrm{~cm}$ dan plat lantai $12 \mathrm{~cm}$. Dikombinasikan dengan material baja pada struktur atap supaya tahan dengan kondisi lingkungan dan iklim. Penutup atap menggunakan genteng material lokal yang digunakan oleh perumahan masyarakat.

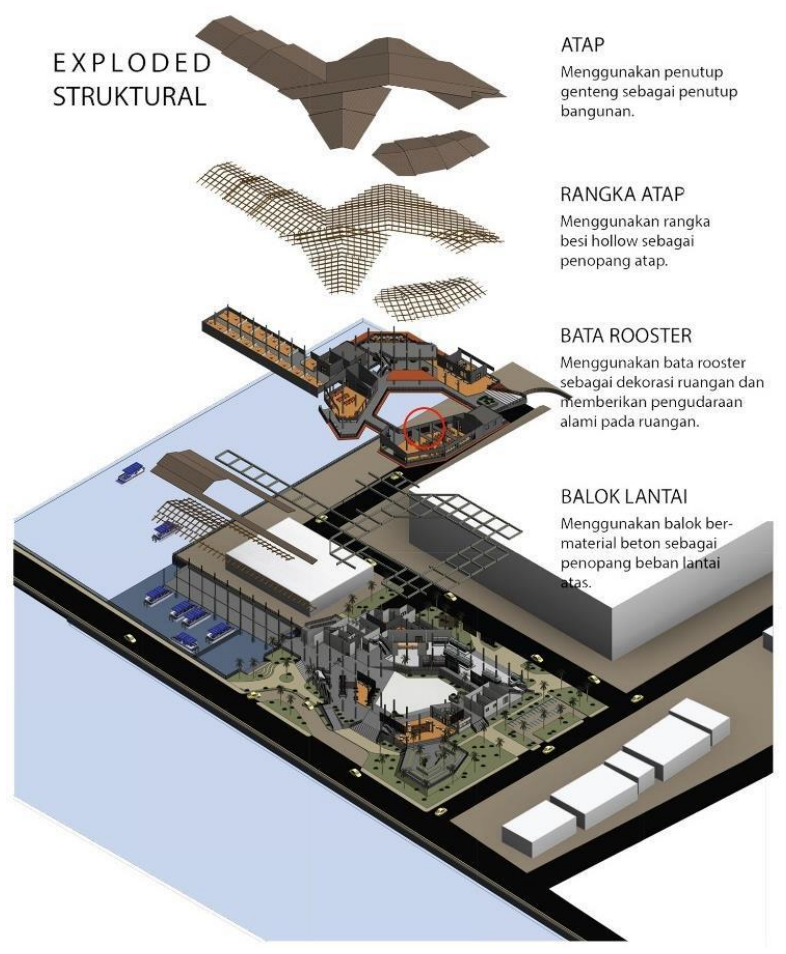

Gambar 2. Struktur Bangunan

Sumber: Dokumentasi Pribadi, 2020 


\section{Hasil Desain}

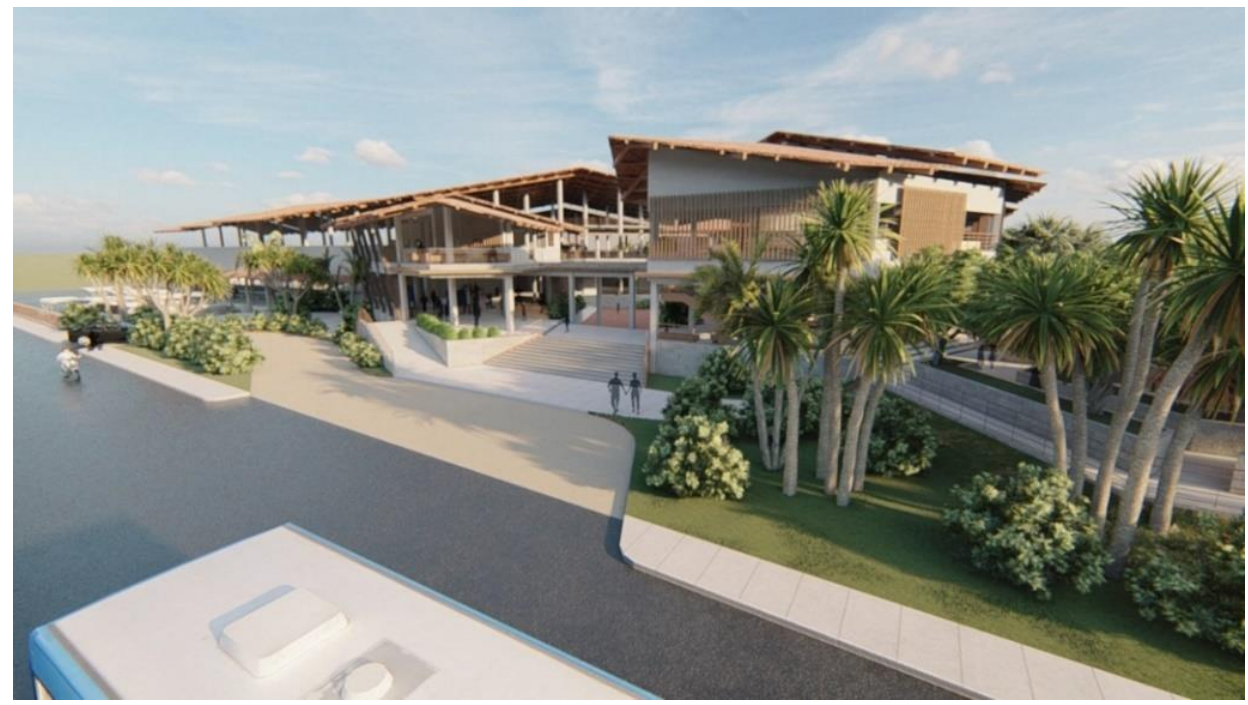

Gambar 3. Perspektif Eksterior

Sumber: Dokumentasi Pribadi, 2020
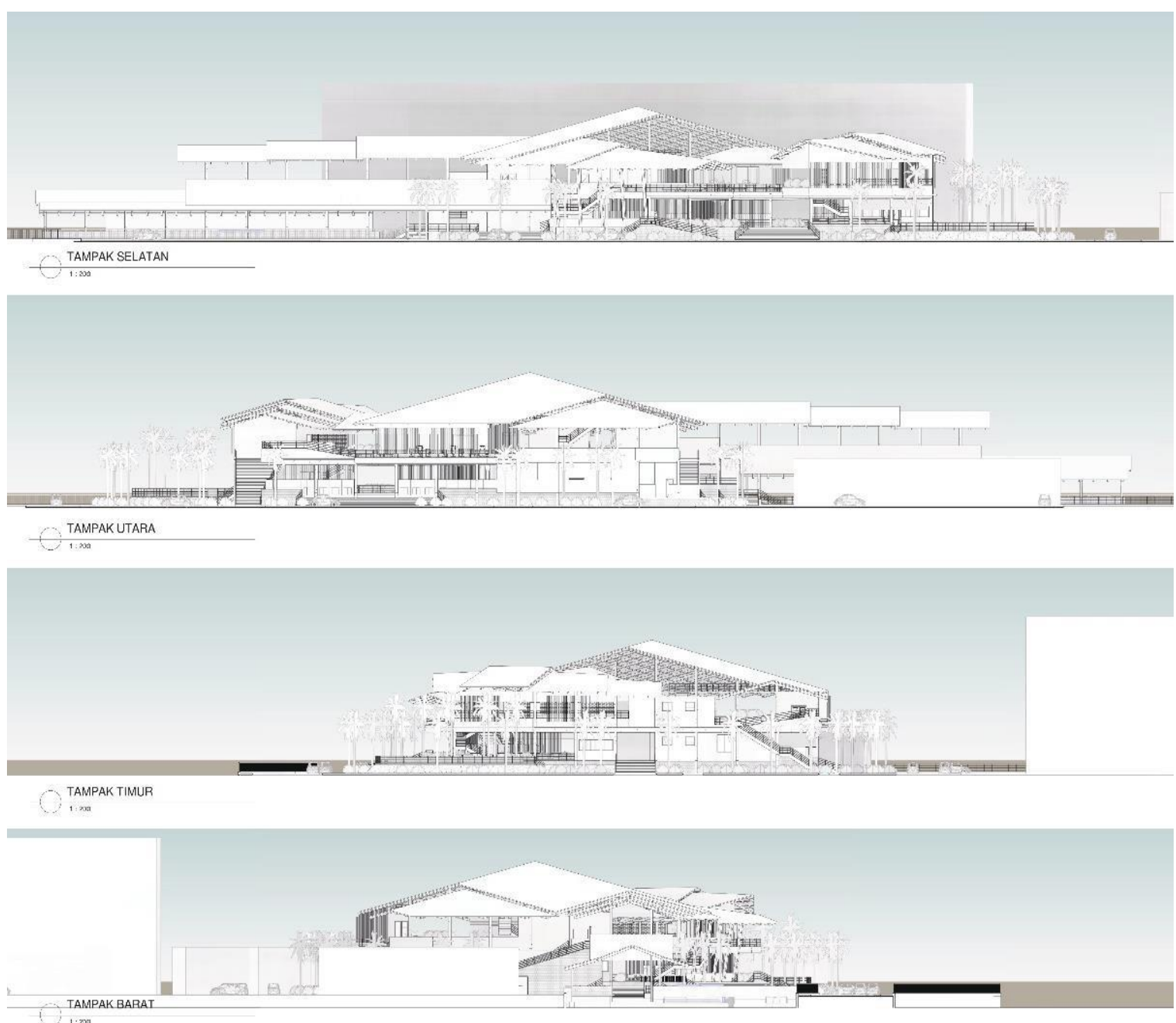

Gambar 4. Tampak Bangunan

Sumber: Dokumentasi Pribadi, 2020 
Bangunan ini dibuat dengan pendekatan regionalisme, di mana pada pendekatan ini bangunan menggunakan bahan-bahan yang digunakan masyarakat lokal yang akan merespon keadaan iklim kawasan ini. Fasad dibuat dengan banyaknya bukaan untuk memberikan kesan ringan dan terbuka dengan memperhatikan konsep low profile untuk memberikan kesan tidak 'mengintimidasi', dengan desain yang menggambarkan arsitektur tropis daerah pinggir laut. Menggunakan material baja dan beton, di mana baja dicat hingga menyerupai kayu guna memberikan kesan lokal dan kuat terhadap kondisi iklim. Tapak didesain dengan banyaknya penghijauan untuk memaksimalkan penghijauan di kawasan yang padat dan gersang. Adanya ruang hijau dapat memberikan tempat refreshing di antara bangunan-bangunan dan lahan pengeringan ikan.

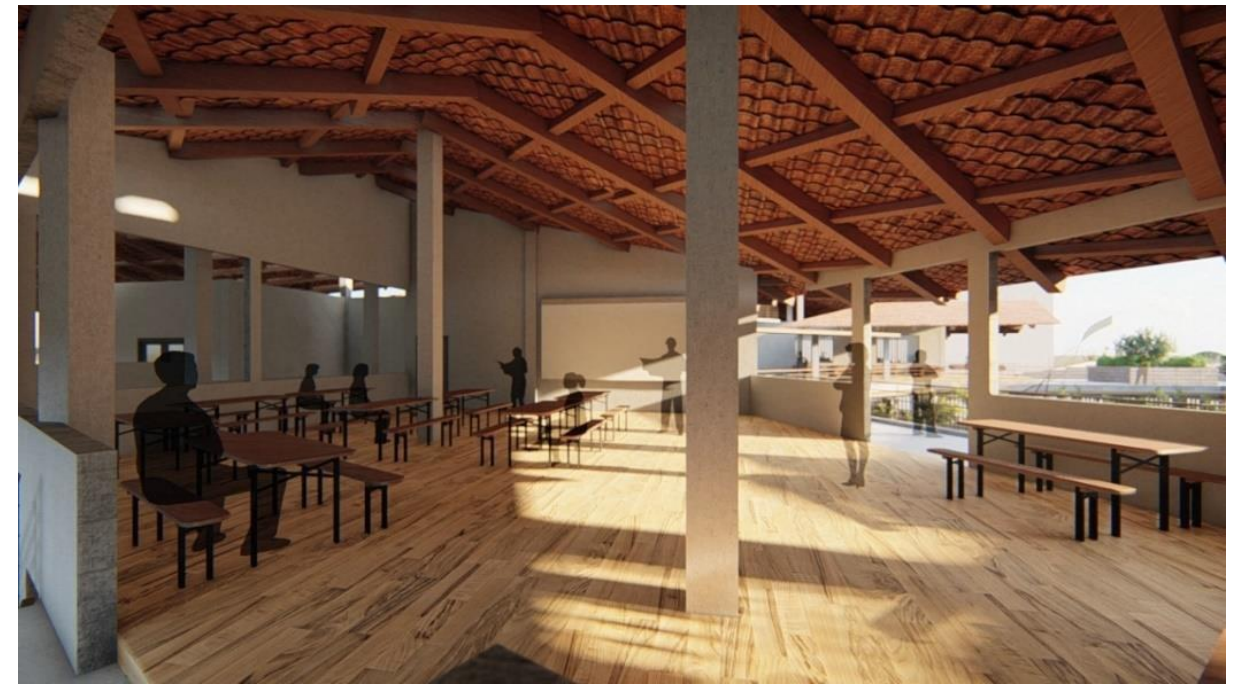

Gambar 5. Perspektif Interior

Sumber: Dokumentasi Pribadi, 2020

Pada Interior bangunan ini dibatasi dengan setengah dinding untuk memberikan bukaan pada ruang-ruang yang ada. Selain itu berguna untuk menghilangkan kesan tertutup karena pada dasarnya bangunan ini terbuka untuk umum sehingga dapat diakses oleh semua orang.

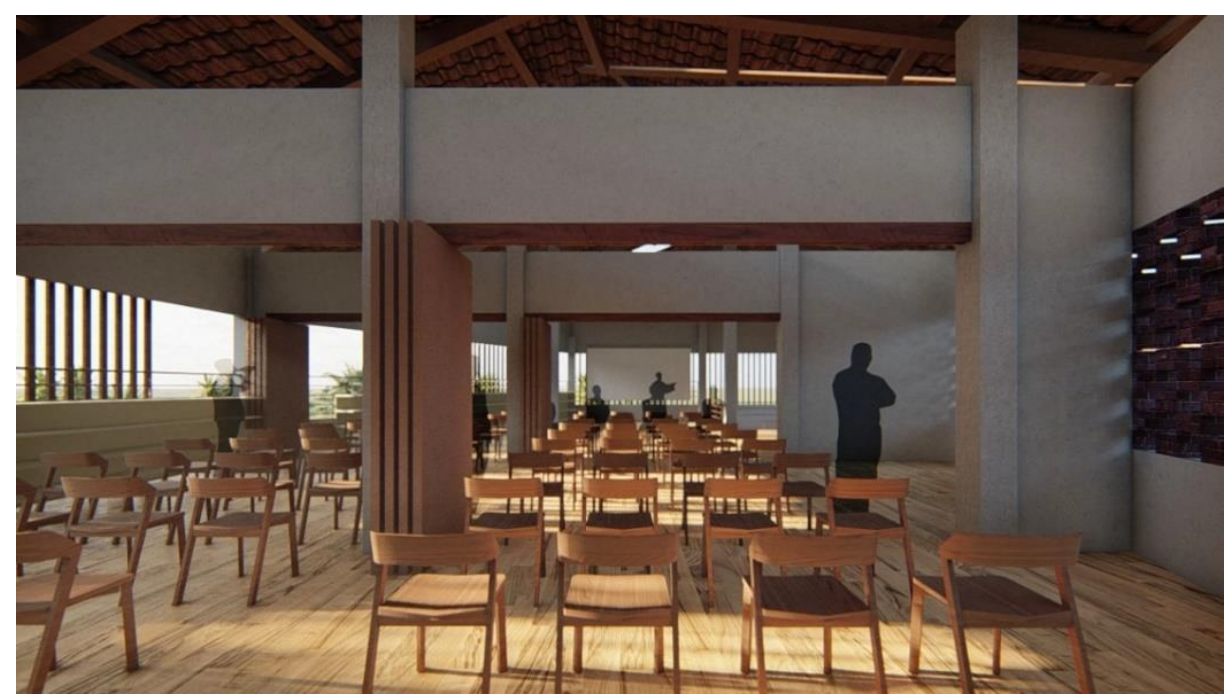

Gambar 6. Perspektif Interior

Sumber: Dokumentasi Pribadi, 2020 


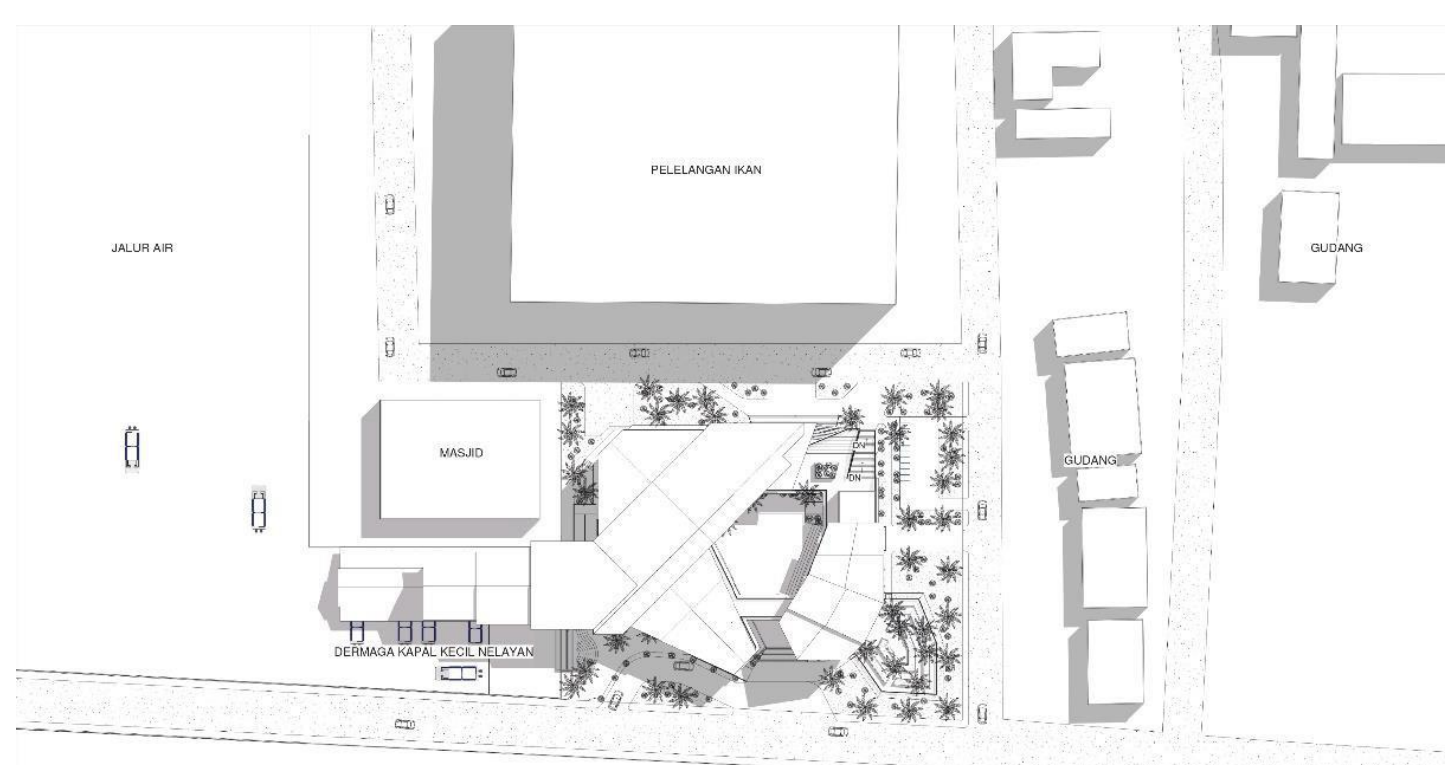

Gambar 7. Gambar Block Plan

Sumber: Dokumentasi Pribadi, 2020

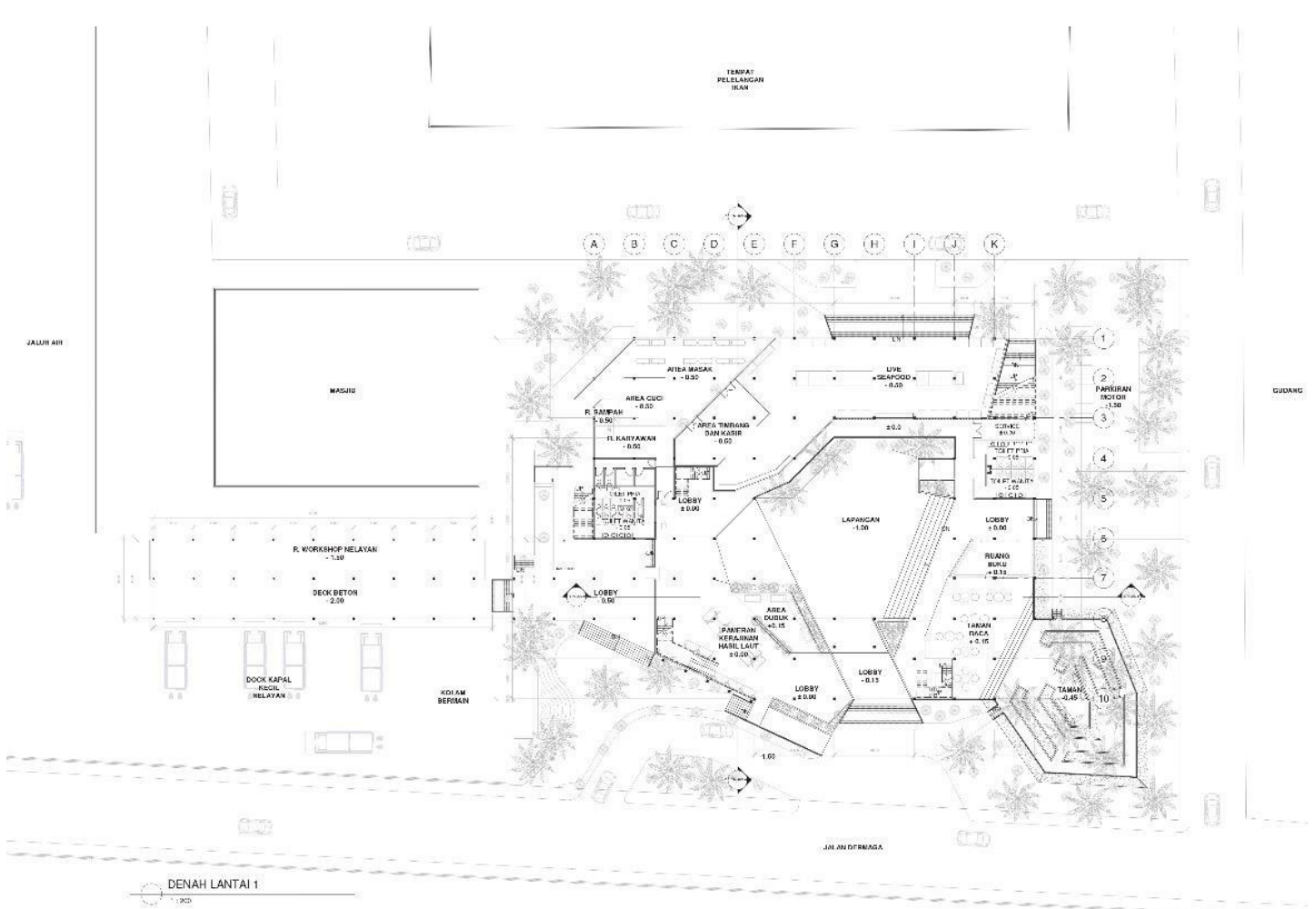

Gambar 8. Gambar Denah Lantai 1

Sumber: Dokumentasi Pribadi, 2020 


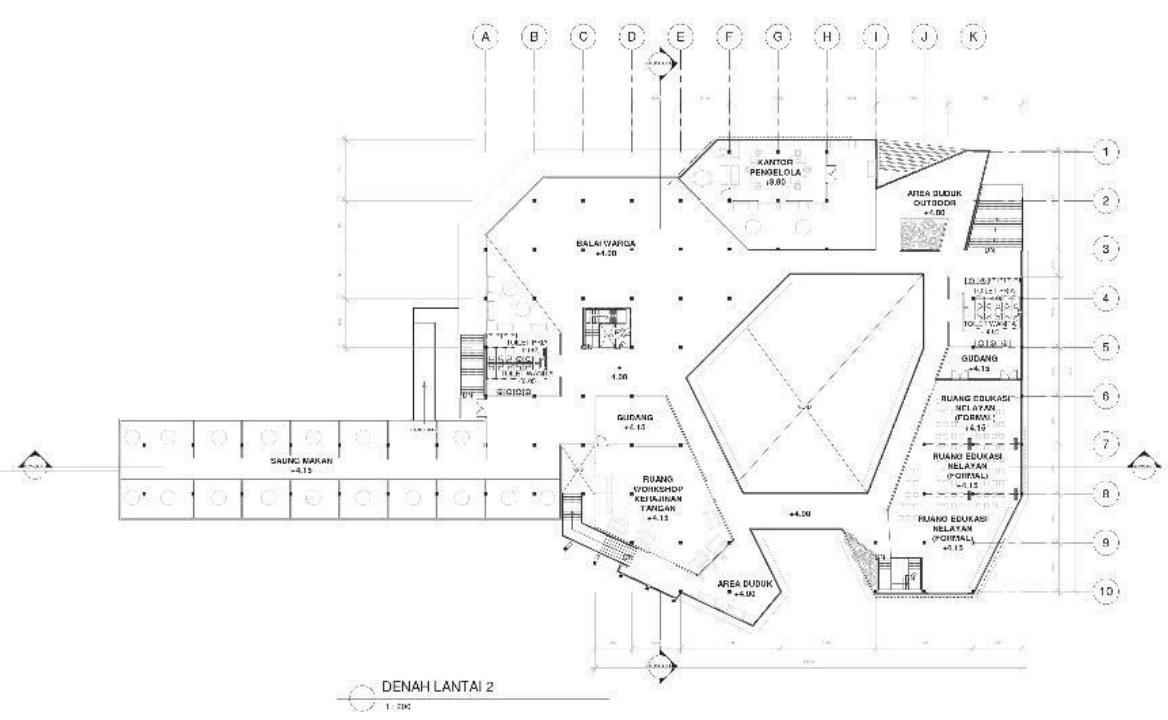

Gambar 9. Gambar Denah Lantai 2

Sumber: Dokumentasi Pribadi, 2020

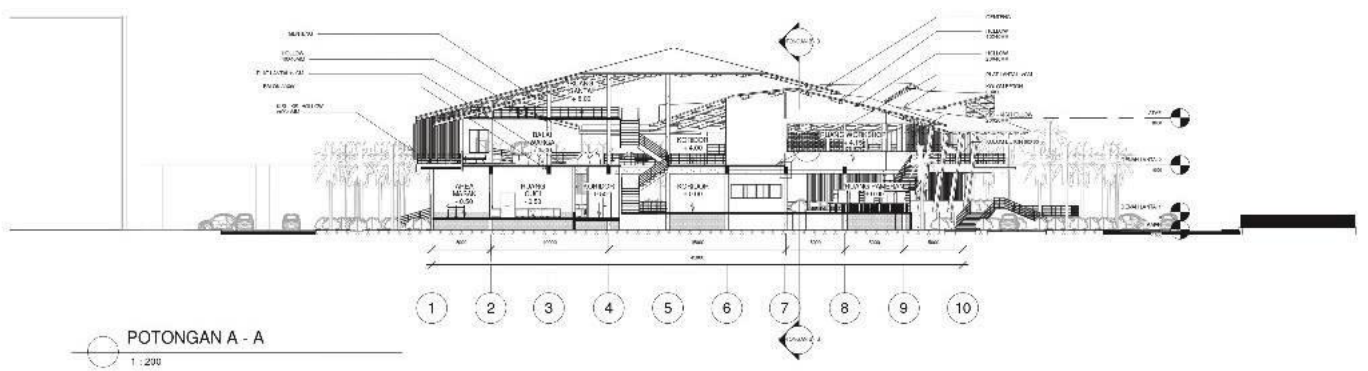

Gambar 10. Gambar Potongan A-A

Sumber: Dokumentasi Pribadi, 2020

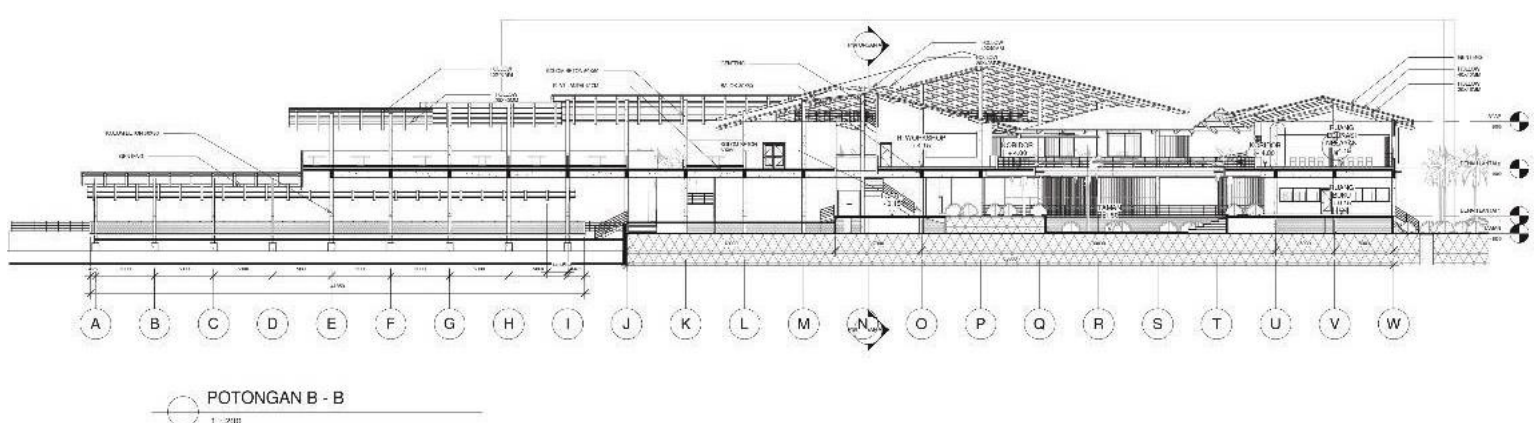

Gambar 11. Gambar Potongan B-B

Sumber: Dokumentasi Pribadi, 2020 


\section{KESIMPULAN}

Proyek akan menghadirkan sebuah third place yang mampu mewadahi kebutuhan masyarakat khususnya di daerah Muara Angke dengan mengangkat masalah yaitu kurangnya ruang public untuk berkumpul dan kurangnya masyarakat yang tingkat pendidikannya cukup di sana, yang diharapkan dengan terbentuknya proyek ini masyarakat kota dapat memiliki tempat beraktivitas bersama secara layak dan nyaman serta dapat memberikan tambahan pendidikan untuk meningkatkan pengetahuan dalam melakukan aktivitas harian dengan kinerja dan hasil yang lebih baik sehingga dapat membantu kehidupan mereka nantinya. Berdasarkan kebutuhan tersebut, proyek ini akan memiliki 3 program utama yaitu:

a. Education dengan fungsi berupa ruang edukasi untuk masyarakat lokal secara formal maupun informal;

b. Communal dengan berupa ruang-ruang berkumpul untuk beraktivitas bersama, serta;

c. Food and Beverages berupa restoran.

\section{REFERENSI}

Maria \& Burke, B. (2009). Fundamentals of Integrated Design for Sustainable Building. New Jersey: John Wiley \& Sons.

Oldenburg, R. (1997). The Great, Good Place. Cambridge: Da Capro Press.

Pitts, A. (2004). Planning and Design Strategies for Sustainability and Profit: Pragmatic sustainable design on building and urban scales. Elsevier: Architectural Press.

Ward, I. C. (2004). Energy \& Environmental Issues for the practicing architect. London: Thomas Telford.

Williams, D. E. (2007). Sustainable Design: Ecology, Architecture, and Planning. New Jersey: Wiley. 